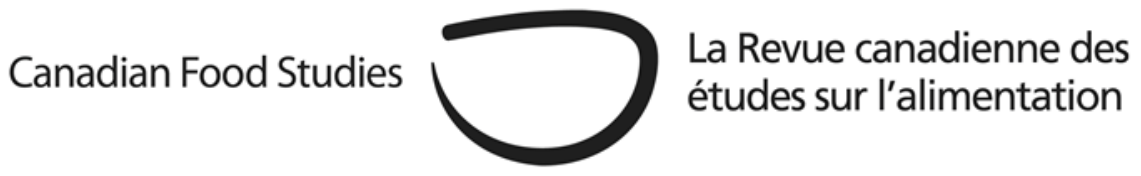

Review Article

\title{
Exploring experiences of food insecurity, shame, stigma, and social exclusion among women in high-income countries: $A$ narrative review
}

Chloe Pineau ${ }^{\mathrm{a}^{*}}$, Patricia L. Williams ${ }^{\mathrm{a}}$, Jennifer Brady ${ }^{\mathrm{a}}$, Madeleine Waddington ${ }^{\mathrm{b}^{* *}}$, and Lesley Frankc

${ }^{a}$ Mount Saint Vincent University

${ }^{b}$ Nova Scotia Health Authority

${ }^{\mathrm{c}}$ Acadia University

\section{Abstract}

In Canada, over 4.4 million people experience food insecurity, a serious public health issue characterized by inadequate or insecure access to food due to financial constraints.

Globally, women experience disproportionately high rates of food insecurity, which is a highly stigmatizing experience that is associated with feelings of shame and social isolation. This narrative review explores how and why social beliefs and stigma contribute to social exclusion among women experiencing food insecurity within high-income countries, along with how enhancing the capacity for empathetic responses to feelings of shame, and efforts to strengthen women's resistance, can lead to a reduction in stigma. The thematic analysis of the articles included in this review identified four themes: 1) the mechanisms of food insecurity-related social exclusion; 2) shame, stigma, and social exclusion associated with the use of charitable food programs; 3) women's experiences with food insecurity, shame, stigma, and social exclusion; and 4) empathy, shame resilience, and resistance. 
The findings of this review suggest that dominant responses to food insecurity contribute to shame, stigma, and social exclusion among women, and that the inadequacy of existing policy responses to address food insecurity has wide-reaching ramifications for the health and well-being of women and their families. Sharing these intersecting lived experiences of food insecurity, shame, and stigma may be an important strategy for building empathy among others and forming a collective resistance in broader society against the systemic injustices at the root of poverty.

Keywords: Household food insecurity; women's experiences; stigma; shame; resilience; resistance

\section{Introduction}

Over 4.4 million Canadians lived in food insecure households in 2017/2018 (Tarasuk \& Mitchell, 2020). Household food insecurity is a serious public health issue that results in significant cost to the health care system, as well as in negative outcomes for individuals' physical health and life expectancy, social and mental well-being, overall quality of life, and healthy child development (Collins, 2009; Hamelin et al., 1999; Men et al., 2020; Middleton et al., 2018; Tarasuk et al., 2015). Statistics Canada (2020) documented a 40\% increase in household food insecurity in May 2020 due to the economic fallout of the COVID-19 pandemic and stated that this is likely an underestimate.

Food insecurity is widely recognized as the "limited or uncertain availability of nutritionally adequate and safe foods or limited or uncertain ability to acquire acceptable foods in socially acceptable ways" (Anderson, 1990, p. 1598). The findings of Canadian research on lowincome mothers' experiences with household food insecurity are consistent with the seminal findings of Radimer and colleagues (1990), revealing that the experience encompasses four components: quantitative (food depletion), qualitative (unsuitable food), psychological (food anxiety), and social (food acquisition in socially unacceptable ways). While the manifestation of food insecurity is dynamic and may differ among individuals within the same household, the four components at the individual level generally present as insufficient intake of food, compromised dietary quality, feelings of deprivation or lack of choice, and disrupted eating patterns, respectively (Hamelin et al., 2002; Radimer et al., 1990; Tarasuk, 2001; Williams et al., 2010, 2012). In Canada and other high-income countries, the prevalence and severity of household food insecurity is measured based on inadequate or insecure access to food due specifically to financial constraints, and it is considered a powerful indicator of broader material deprivation (Tarasuk \& Mitchell, 2020).

Both locally and globally, women experience disproportionately high rates of food insecurity relative to their male counterparts (Collins, 2009; Martin et al., 2016). 
One in three female-led, lone-parent households in Canada experienced food insecurity in 2017/2018, the highest rate of all household types (Tarasuk \& Mitchell, 2020). Lone mothers are especially vulnerable to both food insecurity and its negative physical and psychological health outcomes, including dietary inadequacy, chronic illness, social exclusion, depression, mental illness, and feelings of inferiority and shame (Carter et al., 2011; Ciciurkaite \& Brown, 2018; Collins, 2009; Hanson, 2011; Lawlis \& Jamieson, 2016; Martin et al., 2016; Power et al., 2014; Williams et al., 2012; Wu \& Schimmele, 2005).

Shame is a self-conscious emotion that occurs when a person is, or perceives that they are, being seen or judged to be fundamentally flawed or inadequate (Brown, 2006; Dolezal \& Lyons, 2017). Shame can also result when an individual is perceived to be deviating from sociocultural expectations and norms and thus failing to live up to social standards (Brown, 2006; Dolezal \& Lyons, 2017). Experiences of shame are inextricably linked to interpersonal relationships and can jeopardize a person's feeling of social acceptance due to the self-conscious nature of shame and its association with a heightened sense of visibility and self-awareness (de Hooge et al., 2018; Dolezal \& Lyons, 2017). Actual or anticipated experiences with shame tend to elicit social withdrawal, leading to feelings of alienation and social isolation (Brown, 2006; de Hooge et al., 2018; Dolezal \& Lyons, 2017). As a result, shame can have a detrimental effect on an individual's mental and psychological health and well-being (Dolezal \& Lyons, 2017; Martin et al., 2016).

Social stigmatization occurs when the traits or behaviours of a person or group of people are perceived to be different from, or inferior to, sociocultural standards, as well as when judgements or stereotypes are attributed to them because of this perceived difference (Ahmedani, 2011). In their international scoping review on the experiences of food bank users in highincome countries, Middleton et al. (2018) differentiate between experiences of "enacted" and "felt" stigma. Enacted stigma refers to explicit experiences with stigmatization and judgement, while felt stigma comprises the anticipation of enacted stigma, an individual's own recognition of their stigmatized identity, and the shame they feel as a result (Middleton et al., 2018). Experiences with felt stigma can cause individuals to internalize stigma by accepting the associated stereotypes and judgement as true and valid, which may damage their self-image and psycho-social well-being (Middleton et al., 2018; Whittle et al., 2020). Like shame, stigmatization can also threaten a person's social ties because others may distance themselves from a stigmatized individual, leading to social exclusion.

Being food insecure is highly stigmatized (Martin et al., 2016; Power et al., 2014; Rosa et al., 2018; Thompson et al., 2018; Wu \& Schimmele, 2005). Individuals are often blamed for being food insecure, and are viewed as lazy, uneducated, or uncaring about their health (Hamelin et al., 2002; Purdam et al., 2016; Thompson et al., 2018). The experience of food insecurity induces feelings of shame, guilt, alienation, and social isolation, particularly among women (Hamelin et al., 1999; McIntyre et al., 2003; Power, 2005; Williams et al., 2010, 2012). 
The urgency of understanding and addressing stigma as a key driver of individual and population health inequities was flagged in the 2019 national report on the State of Public Health in Canada (Tam, 2019). Food insecurity-related stigma, however, was not addressed in Tam's (2019) report, and efforts to redress shame related to food insecurity have yet to be fully explored in the published literature. This review aims to fill this gap by providing a synthesis of literature on shame, stigma, and social exclusion associated with household food insecurity, including research foci and key findings, knowledge gaps, and directions for future research, with a particular view to the experiences of women.

\section{Methodology and methods}

This narrative review was undertaken to support a larger Social Sciences and Humanities Research Council-funded project called Dismantling Stigma, which comprises two objectives: 1) understanding how stigma contributes to social exclusion among women experiencing household food insecurity; and 2) redressing stigma using participatory action research. A narrative review is considered the most appropriate method to obtain a broad perspective on an issue where there is a lack of published literature, as was the case for this research (Green et al., 2006). Drawing upon systematic methods, a narrative review is intended to bridge theory and context, provoke thought, and support scholarly discussion and further inquiry, rather than to provide an assessment of the efficacy of the methods employed in the published studies (Green et al., 2006).

The primary researcher (C. P.) independently performed an initial literature search using the following databases: Google Scholar, EBSCO, SocIndex, PsycInfo, PubMed, and ERIC. Relevant scholarly peer-reviewed literature was identified by applying the following search strategy, combining free words and MESH terms: (household food insecurity OR food insecurity) AND (women's experiences OR women OR gender) AND (stigma OR shame OR social exclusion OR marginalization) AND (empathy OR shame resilience). Initially, the search focused on women's experiences within a Canadian context; however, the availability of relevant literature was limited. As a result, inclusion criteria were subsequently expanded to include all high-income countries and any experiences with household food insecurity, rather than women's experiences specifically. Articles were excluded if they were not available in full text, were not published in English, or were published before 2000. The literature search was augmented by both a manual search of reference lists of the articles retrieved and by the identification of other published and "grey" literature by the research team to fill in missing evidence (Ferrari, 2015).

Initially, the titles and abstracts of all articles were screened independently by the primary researcher (C. P.), and duplicate articles were removed. Articles that met the inclusion criteria were added to a Microsoft Excel file. 
Each selected article was read through once and then critically evaluated, extracting the following data when available, which was subsequently added to Microsoft Excel: study citation, publication type (e.g., published or unpublished), study type (e.g., quantitative, qualitative, or mixed method), study characteristics (e.g., study location, setting, and use of control), participant characteristics (e.g., number, age, and study inclusion/exclusion criteria), intervention details (e.g., length and type), and outcome measures and study results (e.g., quantitative results, qualitative themes, recommendations, key learnings, and insights).

The initial literature search identified 91 articles; of the 82 articles with full-text available, 35 met the inclusion criteria. An additional 20 references were added through the manual search. Of the 55 articles identified as meeting the criteria, 45 sources with the best contributions to address the research question were selected for synthesis (Ferrari, 2015). Of the 45 sources selected, 38 involved original research, 7 were reviews/syntheses, 19 employed qualitative methods, 13 employed quantitative methods, and 6 employed mixed methods. The selected articles were uploaded to MAXQDA, read a second time, and coded using a process of open coding (Castleberry \& Nolen, 2018; Strauss \& Corbin, 1990; VERBI Software, 2018). The coding strategy evolved during the coding process as conceptual themes emerged from the literature. "Codes" served as labels to categorize and retrieve relevant sections from the data (Castleberry \& Nolen, 2018). The activity of coding involved attaching codes to units of data within the document that were related to the overarching conceptual theme associated with a particular code (Castleberry \& Nolen, 2018). Through an iterative process, conceptual themes representing patterns within the data, such as the social functions of food and women's experiences with food insecurity, were identified and peer reviewed by the research team.

\section{Results and Discussion}

The thematic analysis of the articles included in this narrative review identified four overarching themes: 1) the mechanisms of food insecurity-related social exclusion; 2) shame, stigma, and social exclusion associated with use of charitable food programs; 3 ) women's experiences with food insecurity, shame, stigma, and social exclusion; and 4) empathy, shame resilience, and resistance.

\section{The mechanisms of food insecurity-related social exclusion}

There are several potential mechanisms through which food insecurity can contribute to stigmatization, shame, and social exclusion. 
In Canada, dominant healthy eating discourses are perpetuated by dietary guidelines such as Canada's Food Guide, which was recently revised by Health Canada (2019). Canada's Food Guide offers a visual representation of what constitutes a "healthy" diet and provides several recommendations for how to "eat well [and live] well," such as eating "a variety of healthy foods each day," and including protein foods, whole grains, and "plenty of vegetables and fruits" to achieve a healthy diet (Health Canada, 2019, p. 1). This type of information establishes societal expectations about how to eat healthily, live healthily, and thus function in socially acceptable ways (Hamelin et al., 2002). Language such as incorporating "plenty" of fresh produce is problematic in that it presents an ideal that is in stark contrast with the everyday inadequacy faced by households experiencing food insecurity (Whittle et al., 2020; Williams et al., 2010, 2012). Similarly, in relation to infant feeding, "breast is best" discourses used in public health promotion serve to frame breastfeeding as a directive rather than a choice. Though unintended, these health promotion messages may contribute to feelings of powerlessness and stigmatization for mothers in their infant feeding decisions, particularly among mothers experiencing food insecurity (Guttman \& Zimmerman, 2000; Knaak, 2005; Waddington, 2016). Food insecurity prohibits individuals from eating and feeding their families in ways that meet societal expectations, which exacerbates stress, feelings of deprivation, and social exclusion (Collins, 2009; Hanson, 2011; Hamelin et al., 2002; Williams et al., 2010, 2012). Research has also shown that "coping" with food insecurity may involve compromising the quality of food, for example by watering down milk or infant formula to "stretch" it, or by adopting sub-optimal feeding practices such as using food substances other than infant formula when not recommended (Frank, 2015; Partyka et al., 2010, Williams et al., 2010, 2012). For women, who are often tasked with feeding and nutritional gatekeeping work within households, the dominance of these healthy eating discourses likely heightens the stigma associated with having to make these choices when struggling to feed their families (Bellows, 2003).

Food insecurity can also result in alienation due to feelings of compromised social standing (Hamelin et al., 2002). While varied diets are associated with privilege, food insecurity is often characterized by limited and "impossible" food choices along with a monotonous diet that lacks options for creative, pleasure-focused, or values-based food choices (Cairns \& Johnston, 2015; Hamelin et al., 2002; McIntyre et al., 2007; Williams et al., 2010). Certain types of foods that are imbued with heightened cultural capital, such as organic produce and fair-trade beverages, tend to be associated with higher social status, but these types of foods are likely not accessible for households experiencing food insecurity (Hamelin et al., 2002; Williams et al., 2012). Even milk, a food that is considered a healthy staple for its calcium and vitamin D content, was found to be seen as an "elite commodity" by food insecure mothers in Atlantic Canada (McIntyre et al., 2007). When food insecure households are forced to manage their families' nutritional needs and food preferences with inadequate food budgets, they are limited to purchasing both less nutritious food items and foods that mark them and their families as belonging to a lower social class, and thus being of perceived lower social value (Hamelin et al., 2002; Lawlis \& Jamieson, 2016; Tarasuk, 2001; Williams et al., 2012). 
These "impossible" choices are also demonstrated in the context of infant feeding, where mothers living with food insecurity are constrained by multiple factors, including the lack of affordability of infant formula or a basic nutritious diet for breastfeeding mothers (Frank et al., 2020). A lack of social policy and social stigma may prevent food insecure households from exercising true choice around how to feed their infants (Frank, 2015; Waddington, 2016). While weak economic protections, including inadequate income assistance and maternal and child benefits, create the conditions necessary for maternal and infant food insecurity to exist in highincome countries, these outcomes are often experienced as personal failures related to not being able to "properly" feed one's child (Frank, 2015, 2020; Frank et al., 2020). The experience of being restricted to a diet that is socially devalued and considered to be inferior or substandard can be demeaning, and results in a damaged social image and feelings of shame and deprivation (Hamelin et al., 2002).

The importance of food extends beyond basic nutritional requirements to encompass aspects of a person's identity, culture, and social activities, as well as their sense of connection and belonging (Hanson, 2011; Martin et al., 2016; Purdam et al., 2016). Food insecurity may limit an individual's capacity to express their values through food, share meals with others, or celebrate special occasions (Harmon et al., 2017; Wu \& Schimmele, 2005). The inability to fully participate in social activities and in one's community, which accompanies the experience of food insecurity, amplifies existing feelings of social isolation related to material deprivation itself (Martin et al., 2016).

\section{Shame, stigma, and social exclusion associated with the use of charitable food programs}

Numerous studies have documented the shame, stigma, embarrassment, and social isolation associated with the use of charitable food programs, most notably food banks, along with many other limitations and negative repercussions (Frank, 2020; Martin et al., 2016; Middleton et al., 2018; Power et al., 2014; Tarasuk et al., 2014a). Food banks are often unable to offer varied, high-quality food items, which constrains users' food choices and their ability to meet dietary needs (Frank, 2018; Hamelin et al., 2002; Middleton et al., 2018; Purdam et al., 2016; Riches, 2002; Tarasuk et al., 2014a). Food bank users are also often understood as "recipients" rather than "consumers" of food, which reinforces a lack of control and powerlessness that can damage their sense of identity, pride, and self-worth (Middleton et al., 2018; Purdam et al., 2016; Thompson et al., 2018). This may further undercut food bank users' sense of autonomy over their food choices, and, by extension, their ability to manage health concerns, as well as to meet preferences for spiritual, cultural, or moral reasons (Hamelin et al., 2002; Middleton et al., 2018; Purdam et al., 2016; Riches, 2002). 
Individuals reporting food insecurity often resort to using coping strategies other than food banks to feed themselves and their families; while there are many reasons for this, stigma is a common factor associated with the avoidance of food banks. Food bank users often describe having no choice but to adopt food acquisition strategies that are viewed as socially unacceptable, resulting in a reduced sense of autonomy and control, fear of being judged, and shame and self-judgement (Hamelin et al., 2002; Martin et al., 2016; Middleton et al., 2018; Power et al., 2014; Purdam et al., 2016; Rosa et al., 2018; Tarasuk et al., 2019; Thompson et al., 2018). For many, the decision to visit a food bank is initially met with hesitation and reluctance, and it is often considered as a last resort after feelings of shame and embarrassment have been overcome (Hamelin et al., 2002; Purdam et al., 2016). The hidden costs of food banks, namely the stigma and indignity surrounding their use, can be so great that they can prevent individuals experiencing food insecurity from accessing them at all, regardless of the extent of their need (Hamelin et al., 2002; Middleton et al., 2018; Power et al., 2014; Purdam et al., 2016). This is evidenced by the finding that only $20-30 \%$ of Canadians experiencing food insecurity utilize charitable food programs (Tarasuk et al., 2014a).

In recent years, recognizing the limitations of food banks, some charitable and community-based food programs have transitioned away from traditional food assistance models into supermarket-style "food hubs," and have partnered with small-scale producers in an effort to provide individuals experiencing food insecurity with the ability to access affordable, healthy, and sustainable food in a more dignified and socially acceptable way (McNaughton et al., 2021; Psarikidou et al., 2019). While this expansion of services, including community-based food centres, may have benefits for participating families, it can expose a family's struggle to access food to others in the community, and may elicit feelings of embarrassment and shame for program participants (McNaughton et al., 2021; Psarikidou et al., 2019; Rosa et al., 2018). Participation in other types of charitable and community-based food programs may also contribute to feelings of inadequacy related to users' own perceptions that they are unable to provide for themselves and/or their families (Middleton et al., 2018). They often fear that being seen by others in their community as the recipients of charity will result in judgement and a negative social image, which can be detrimental to their self-esteem, reputation, and sense of dignity (Middleton et al., 2018; Purdam et al., 2016). Similarly, programs that focus on building food skills, such as cooking programs or community kitchens, may operate on the assumption that individuals facing food insecurity have a knowledge deficit in this area, despite research to the contrary (Huisken et al., 2016).

The resulting judgement and internalized stigma associated with using food banks and other charitable and community-based food programs can lead to detachment from society and rejection of potential sources of help, which can further compound social isolation, and thereby worsen the severity of food insecurity (Purdam et al., 2016). Not only are food banks and other charitable and community-based food programs an inadequate response to food insecurity that fails to address root causes, but they also fail to respond fully to the needs of those they intend to serve and create stigma surrounding their use. 
This, in turn, leads to negative impacts on physical and psycho-social health (Hamelin et al., 2002; Middleton et al., 2018; Power et al., 2014; Riches, 2002; Tarasuk et al. 2019).

\section{Women's experiences with food insecurity, shame, stigma, and social exclusion}

The higher risk of experiencing food insecurity and its negative physical and psycho-social health outcomes faced by women, particularly lone mothers, compared to their male counterparts is related to underlying gender inequities. Gender inequities have been well documented and include disproportionately high rates of poverty, income inadequacy, and single parenthood among women, gendered familial roles and responsibilities, sociocultural expectations, perceptions of self-worth, and the subservient role of women created in part by the historical movement from matriarchal to patriarchal structures in society (Collins, 2009; Kerr et al., 1988; Matheson \& McIntyre, 2013; Muldoon et al., 2013).

Parents are typically subjected to greater social scrutiny than adults without children, but mothers tend to be particularly vulnerable to social judgement because of gendered sociocultural expectations regarding women's familial roles and responsibilities (Ciciurkaite \& Brown, 2018; Hanson, 2011). Even within dual-parent households, women are more likely to assume primary responsibility for household tasks such as childcare and managing household food resources, including the procurement, production, and preparation of food (Hanson, 2011; Martin et al., 2016; Matheson \& McIntyre, 2013; Muldoon et al., 2013). In Canada, like in many other developed countries, women have been socialized to adopt the traditional domestic roles of caregiver and food provider, and, consequently, they are subjected to the social expectations that accompany these roles (Carter et al., 2011; Hanson, 2011; Matheson \& McIntyre, 2013; Muldoon et al., 2013). As a result, mothers most often shoulder a disproportionate share of the psychological and emotional burdens related to household food insecurity, leading to gender inequities in the distribution of negative psychological effects of household food insecurity (Ciciurkaite \& Brown, 2018; Hanson, 2011; Thompson et al., 2018). This is particularly evident for breastfeeding mothers, who have a unique role within the family in relation to infant feeding practices as the co-producers of infant food through lactation (Frank, 2015). Mothers are uniquely susceptible to concerns surrounding the inability to produce what they perceive as sufficient breast milk, both in terms of quantity and quality; as a result, feeding infants in comparison to feeding others is arguably more enshrined in ideas about mothers' natural disposition for family food work (Frank, 2018). Furthermore, for breastfeeding mothers experiencing food insecurity, assumptions around cost savings as the primary motivator for breastfeeding have also been shown to be stigmatizing (Waddington, 2016). Conversely, there is also stigma surrounding the decision to formula feed, due to neoliberal discourses that hold mothers responsible for an inability to provide infants with the optimal nutrition associated with breastfeeding (Murphy, 2000). 
These findings demonstrate that both breastfeeding and formula feeding may be socially and culturally unacceptable depending on the context, and that mothers in food insecure households may be particularly susceptible to stigma regardless of how they feed their infant (Waddington, 2016).

Women's social roles as care- and food-providers are related to normative expectations that mothers should prioritize the health and well-being of other family members at the expense of their own (Ciciurkaite \& Brown, 2018; Thompson et al., 2018). Furthermore, mothers' socialized roles as caregivers, which involve monitoring and protecting the health of their children and families, put them at risk of assuming the blame for any poor health outcomes that arise among their family members due to food insecurity (Ciciurkaite \& Brown, 2018; Hanson, 2011). These sociocultural expectations often cause mothers to act as "shock absorbers" for the negative effects of food insecurity on their families, which is demonstrated by the frequent and consistent finding that mothers compromise their own food intake to protect the nutritional needs of their children (Carter et al., 2011; Collins, 2009; Hamelin et al., 2002; Hanson, 2011; Lawlis \& Jamieson, 2016; Matheson \& McIntyre, 2013; McIntyre et al., 2003; Thompson et al., 2018; Williams et al., 2012). The desire to protect their families from the negative effects of food insecurity, and the stress and stigma that arise when they are unable to do so, can have profound implications for women's nutritional, psychological, and physical health and well-being, and, consequently, can also compromise the critical role mothers play in parenting their children (Ciciurkaite \& Brown, 2018; Hanson, 2011; Thompson et al., 2018; Williams et al., 2012). In relation to infant feeding, research has shown that food insecurity may lead mothers to initiate breastfeeding due to perceptions of cost savings; however, when breastfeeding is perceived as a true necessity for financial reasons, mothers may feel that they have no choice but to persevere through breastfeeding challenges despite possible negative impacts on their own physical or mental health (Frank, 2015; Waddington, 2016). When food insecurity compromises mothers' ability to provide food for their families, it also fundamentally undermines their ability to live up to the dominant sociocultural standards that are imposed upon them. Consequently, the inability to fulfill their real or perceived role within the family has been found to lead to feelings of failure, guilt, stress, shame, social exclusion, and alienation among women, negatively impacting their self-esteem and sense of self-worth (Carter et al., 2011; Ciciurkaite \& Brown, 2018; Collins, 2009; Hanson, 2011; Muldoon et al., 2013; Williams et al., 2012).

\section{Empathy, shame resilience, and resistance}

While the shame and stigma that result from food insecurity and unmet social expectations can lead to social isolation and compromised parenting and health, findings from a small pool of published literature suggest that enhancing the capacity for empathetic responses to feelings of shame, along with efforts to strengthen women's resilience to shame, can lead to a reduction in internalized stigma (Brown, 2006; Middleton et al., 2018; Purdam et al., 2016). 
Empathy refers to the ability to perceive a situation from another person's perspective, as well as the ability to convey understanding of their unique position and experience (Brown, 2006; Harmon et al., 2017). In her study on the impact of shame experiences on women, Brown (2006) conceptualized the experience of empathy as the opposite of the experience of shame. From her research, Brown (2006) developed shame resilience theory, which describes the strategies employed by women to develop shame resilience and is centred on the importance of empathy, connection, and a concept called "speaking shame," which refers to a woman's ability to recognize and articulate her shame experiences. When women lack the language and emotional competence to reflect on and identify their shame experiences, shame can be internalized, which can exacerbate feelings of social isolation (Brown, 2006). In contrast, speaking shame allows women to externalize, and thus normalize, these experiences (Brown, 2006). Equipping women with the language to identify and deconstruct their shared experiences with shame can increase their sense of connection and enhance their capacity to develop mutually empathetic relationships, which can in turn alleviate some of the isolating aspects of shame and strengthen women's shame resilience (Brown, 2006; Middleton et al., 2018; Purdam et al., 2016).

Brown's (2006) findings regarding empathy and the power of speaking shame not only have implications for dealing with the experience of food insecurity in more efficacious ways in the short term, but also offer promise for shifting thinking to more comprehensive longer-term solutions to food insecurity. While empathy has long been recognized as an important attribute of health care workers and other service providers, discussion of how these professionals can interact with women experiencing material deprivation, including food insecurity, in ways that help to dismantle feelings of shame and social isolation is limited in the published literature (Harmon et al., 2017). A deeper understanding of lived experiences of stigma and shame may help women affected by food insecurity, and professionals working with them, to better resist dominant narratives around poverty that place responsibility on individuals for their circumstances and can empower them to draw attention to the structural and systemic issues that lie at the root of poverty. Addressing this knowledge gap may also offer important insights for those in other sectors and across society to more broadly understand and relate to those living in poverty, allow them to develop collective resistance to social injustice, and ultimately lead to improved agency to advocate for policy change.

\section{Conclusions and implications}

Recognizing that gaps exist in the published research, the findings of this narrative review point to three key mechanisms whereby food insecurity contributes to stigmatization, shame, and social exclusion, underscoring insights from and limitations of the understandings reflected in the literature: 1) the exclusionary and potentially damaging nature of dominant healthy eating discourses; 2) alienation due to inequities in social standing; and 3) the importance of food for social and cultural identity. 
The findings from this review also suggest that dominant responses to food insecurity, namely traditional food banks, often contribute to shame, stigma, and social exclusion by undercutting users' sense of autonomy over their food choices, inciting fear of judgement based on a family's struggle to access food, and causing individuals to acquire food in ways that they often perceive as socially unacceptable.

This narrative review is not intended as a systematic review of the research that has been published on women's experiences with food insecurity-related shame, stigma, and social exclusion. We have, however, applied systematic methods to examine how and why social beliefs and stigma contribute to social exclusion and shame among women who experience household food insecurity within high-income countries, an area of research that is currently lacking. Moreover, this review provides important insights by bringing together understandings in existing theoretical and empirical published and "grey" literature to support scholarly discussion and future research.

Considered together, the issues raised by this review paint a picture of the current inadequacy of the policy response to address household food insecurity, as it places women, particularly mothers, at risk to become trapped in a cycle of material deprivation and its associated shame because of their unique relationship to food. While food banks and other charitable food programs were intended to be a temporary measure to address food needs in a time of crisis, they have become pervasive as the dominant, and some would argue de facto, policy response to household food insecurity in Canada and many other high-income countries (Martin et al., 2016; Middleton et al., 2018; Power et al., 2014; Tarasuk et al., 2014a). Policy responses have failed to address the well-documented income gap that has been created and deepened by the deterioration of social safety nets with the expansion of neoliberal policies over the past four decades in Canada. Furthermore, the shortcomings of current policies and programs have exacerbated the demands on, and vulnerability of, charitable, ad hoc, and communitydriven responses to household food insecurity, increasingly raising questions as to their adequacy for addressing this issue in a sustainable manner (Tarasuk et al., 2014b).

While this narrative review has highlighted the absence of gender-based analysis in the published literature related to food insecurity in high-income countries, the COVID-19 pandemic has amplified the implications of the current inadequacy of policy response to address household food insecurity in our local and global communities and the wide-reaching ramifications this has for the health and well-being of women and their families. Vulnerable populations, including women, are likely to be disproportionately affected by the increase in the prevalence and severity of food insecurity resulting from the pandemic, particularly due to reduced participation in paid work or education by women who hold a larger proportion of childcare responsibilities (Wall, 2021). These issues further highlight the pressing need for approaches that improve the material conditions of women's lives, and consequently those of their children. 
Brown's (2006) theory of shame resilience, in which the practices of empathy, connection, and "speaking shame" enhance the capacity for empathetic responses to shame experiences and strengthen women's resilience to shame, offers promise for addressing the farreaching implications of the issues highlighted by this research. The finding that limited empirical research has applied shame resilience theory and the insights from this body of work to the experience of food insecurity among women points to the need for further research in this area, particularly with respect to implementation science, including the role of participatory processes in redressing shame and building shame resilience and resistance. Our work on the engagement of women with experiences of food insecurity critically examines the underlying structural determinants of food insecurity through a unique model of participatory food costing (Johnson et al., 2015; Monteith et al., 2019; Williams et al., 2012; Williams, 2014). The results indicate that the creation of a supportive environment that allows women to speak shame and experience empathy and connection contributes to capacity building at individual levels with the potential for positive impacts at the organizational, community, and systems levels within which women are engaged (Monteith et al., 2019; Johnson et al., 2015; Williams, 2014). Consistent with our experience, the findings of this review suggest that sharing the intersecting lived experiences of food insecurity, shame, and stigma offers promise for building empathy among others and developing a collective resistance in broader society against the systemic injustices at the root of poverty. Given that "stigma affects us all [and] we are all vulnerable to the slow and insidious practice of dehumanizing others" (Tam, 2019, p. 5), this narrative review fills an important gap and points to a need to examine intersectionality with respect to food insecurity-related stigma.

Declaration of interest statement: The authors declare that they have no conflict of interest.

\section{References}

Ahmedani, B. K. (2011). Mental health stigma: Society, individuals, and the profession. Journal of Social Work Values and Ethics, 8(2), 1-14.

Anderson, S. A. (1990). Core indicators of nutritional state for difficult-to-sample populations. The Journal of Nutrition, 120(11), 1559-1600. https://doi.org/10.1093/jn/120.suppl 11.1555

Bellows, A. C. (2003). Exposing violences: Using women's human rights theory to reconceptualize food rights. Journal of Agricultural and Environmental Ethics, 16, 249279. https://doi.org/10.1023/A:1023662211010

Brown, B. (2006). Shame resilience theory: A grounded theory study on women and shame. Families in Society, 87(1), 43-52. https://doi.org/10.1606/1044-3894.3483 
Cairns, K., \& Johnston, J. (2015). Food and Femininity. Bloomsbury Academic.

Castleberry, A., \& Nolen, A. (2018). Thematic analysis of qualitative research data: Is it as easy as it sounds? Currents in Pharmacy Teaching and Learning, 10(6), 807-815. https://doi.org/10.1016/j.cptl.2018.03.019

Carter, K. N., Kruse, K., Blakely, T., \& Collings, S. (2011). The association of food security with psychological distress in New Zealand and any gender differences. Social Sciences \& Medicine, 72(9), 1463-1471.https://doi.org/10.1016/j.socscimed.2011.03.009

Ciciurkaite, G., \& Brown, R. L. (2018). Food insecurity, psychological distress and alcohol use: Understanding the salience of family roles for gender disparities. Health Sociology Review, 27(3), 293-311. https://doi.org/10.1080/14461242.2018.1461574

Collins, L. (2009). The impact of food insecurity on women's mental health: How it negatively affects children's health and development. Journal of the Association for Research on Mothering, 11(1), 251-262.

de Hooge, I. E., Breugelmans, S. M., Wagemans, F. M. A., \& Zeelenberg, M. (2018). The social side of shame: Approach versus withdrawal. Cognition and Emotion, 32(8), 1671-1677. https://doi.org/10.1080/02699931.2017.1422696

Dolezal, L., \& Lyons, B. (2017). Health-related shame: An affective determinant of health? Medical Humanities, 43(4), 257-263. https://doi.org/10.1136/medhum-2017-011186

Ferrari, R. (2015). Writing narrative style literature reviews. Medical Writing, 24(4), 230-235. https://doi.org/10.1179/2047480615Z.000000000329

Frank, L. (2015). Exploring infant feeding practices in food insecure households: What is the real issue? Food and Foodways, 23(3), 186-209. https://doi.org/10.1080/07409710.2015.1066223

Frank, L. (2018). Finding formula: Community-based organizational responses to infant formula needs due to household food insecurity. Canadian Food Studies Journal, 5(1), 90-112. https://doi.org/10.15353/cfs-rcea.v5i1.230

Frank, L. (2020). Out of milk: Infant food insecurity in a rich nation. University of British Columbia Press.

Frank, L., Waddington, M., Sim, M., Rossiter, M., Grant, S., \& Williams, P. L. (2020). The cost and affordability of growing and feeding a baby in Nova Scotia. Canadian Journal of Public Health, 111, 531-542. https://doi.org/10.17269/s41997-020-00306-5

Green, B. N., Johnson, C. D., \& Adams, A. (2006). Writing narrative literature reviews for peerreviewed journals: Secrets of the trade. Journal of Chiropractic Medicine, 5(3), 101-117. https://doi.org/10.1016\%2FS0899-3467(07)60142-6

Guttman, N., \& Zimmerman, D. (2000). Low income mothers' views of breastfeeding. Social Science and Medicine, 50, 1457-1473. https://doi.org/10.1016/s0277-9536(99)00387-1

Hamelin, A. M., Beaudry, M., \& Habicht, J. P. (2002). Characterization of household food insecurity in Québec: Food and feelings. Social Science \& Medicine, 54(1), 119-132. https://doi.org/10.1016/s0277-9536(01)00013-2 
Hamelin, A. M., Habicht, J. P., \& Beaudry, M. (1999). Food insecurity: Consequences for the household and broader social implications. The Journal of Nutrition, 129(2), 525S-528S. https://doi.org/10.1093/jn/129.2.525s

Hanson, Y. (2011). Recipes for food insecurity: Women's stories from Saskatchewan. Prairie Women's Health Centre of Excellence.

Harmon, A., Landolfi, K., Shanks, C. B., Hansen, L., Iverson, L., \& Anacker, M. (2017). Food insecurity experience: Building empathy in future food and nutrition professionals. Journal of Nutrition Education and Behavior, 49(3), 218-227. https://doi.org/10.1016/j.jneb.2016.10.023

Health Canada. (2019). Canada's food guide. https://food-guide.canada.ca/en/

Huisken, A., Orr, S.K., \& Tarasuk, V. (2016). Adults' food skills and use of gardens are not associated with household food insecurity in Canada. Canadian Journal of Public Health, 107(6), e526-e532. https://doi.org/10.17269/cjph.107.5692

Johnson, C. P., Williams, P. L., \& Gillis, D. E. (2015). The capacity building experience of women engaged in determining the cost and affordability of healthy food in Nova Scotia, Canada. Journal of Hunger \& Environmental Nutrition, 10(3), 356-378. https://doi.org/10.1080/19320248.2014.962769

Kerr, C., Charles, N., \& Kerr, M. (1988). Women, Food, and Families. Manchester Press.

Knaak, S. (2005). Breast-feeding, bottle-feeding and Dr. Spock: The shifting context of choice. Canadian Review of Sociology and Anthropology, 42(2), 197-216. https://doi.org/10.1111/j.1755-618x.2005.tb02461.x

Lawlis, T., \& Jamieson, M. (2016). Women's risk of food insecurity. International Journal of Women's Health and Wellness, 2(3), 1-2. http://dx.doi.org/10.23937/2474-1353/1510021

Martin, M. S., Maddocks, E., Chen, Y., Gilman, S. E., \& Colman, I. (2016). Food insecurity and mental illness: Disproportionate impacts in the context of perceived stress and social isolation. Public Health, 132, 86-91. https://doi.org/10.1016/j.puhe.2015.11.014

Matheson, J., \& McIntyre, L. (2014). Women respondents report higher household food insecurity than do men in similar Canadian households. Public Health Nutrition, 17(1), 40-48. https://doi.org/10.1017/s136898001300116x

McIntyre, L., Officer, S., \& Robinson, L. M. (2003). Feeling poor: The felt experience of lowincome lone mothers. Affilia, 18(3), 316-331.

https://doi.org/10.1177\%2F0886109903254581

McIntyre, L., Williams, P., \& Glanville, N. T. (2007). Milk as metaphor: Low-income lone mothers' characterization of their challenges acquiring milk for their families. Ecology of Food and Nutrition, 46(3-4), 263-279. http://dx.doi.org/10.1080/03670240701407640

McNaughton, D., Middleton, G., Mehta, K., \& Booth, S. (2021). Food charity, shame/ing and the enactment of worth. Medical Anthropology, 40(1), 98-109. https://doi.org/10.1080/01459740.2020.1776275 
Men, F., Gundersen, C., Urquia, M. L., \& Tarasuk, V. (2020). Association between household food insecurity and mortality in Canada: A population-based retrospective cohort study. Canadian Medical Association Journal, 192(3), E53-E60. https://doi.org/10.1503/cmaj.190385

Middleton, G., Mehta, K., McNaughton, D., \& Booth, S. (2018). The experiences and perceptions of food banks amongst users in high-income countries: An international scoping review. Appetite, 120, 698-708. https://doi.org/10.1016/j.appet.2017.10.029

Monteith, H., Anderson, B., \& Williams, P. L. (2019). Capacity building and personal empowerment: Participatory food costing in Nova Scotia, Canada. Health Promotion International, 35(2), 1-10. https://doi.org/10.1093/heapro/daz004

Muldoon, K. A., Duff, P. K., Fielden, S. J., \& Anema, A. (2013). Food insufficiency is associated with psychiatric morbidity in a nationally representative study of mental illness among food insecure Canadians. Social Psychiatry and Psychiatric Epidemiology, 48, 795803. https://doi.org/10.1007/s00127-012-0597-3

Murphy, E. (2000). Risk, responsibility, and rhetoric in infant feeding. Journal of Contemporary Ethnography, 29(3), 291-325. https://doi.org/10.1177\%2F089124100129023927

Partyka, B., Whiting, S., Grunerud, D., Archibald, K., \& Quennell, B. (2010). Infant nutrition in Saskatoon: Barriers to infant food security. Canadian Journal of Dietetic Practice and Research, 71(2), 79-84. https://doi.org/10.3148/71.2.2010.79

Power, E. (2005). The unfreedom of being other: Canadian lone mothers' experiences of poverty and 'life on the cheque'. Sociology, 39(4), 643-660. https://doi.org/10.1177\%2F0038038505056023

Power, E. M., Little, M. H., \& Collins, P. A. (2014). Should Canadian health promoters support a food stamp-style program to address food insecurity? Health Promotion International, 30(1), 184-193. https://doi.org/10.1093/heapro/dau080

Psarikidou, K., Kaloudis, H., Fielden, A., \& Reynolds, C. (2019). Local food hubs in deprived areas: De-stigmatising food poverty? Local Environment, 24(6), 525-538. https://doi.org/10.1080/13549839.2019.1593952

Purdam, K., Garratt, E. A., \& Esmail, A. (2016). Hungry? Food insecurity, social stigma and embarrassment in the UK. Sociology, 50(6), 1072-1088. https://doi.org/10.1177\%2F0038038515594092

Radimer, K. L., Olson, C. M., \& Campbell, C. C. (1990). Development of indicators to assess hunger. The Journal of Nutrition, 120(11), 1544-1548. https://doi.org/10.1093/jn/120.suppl 11.1544

Riches, G. (2002). Food banks and food security: Welfare reform, human rights and social policy. Lessons from Canada? Social Policy \& Administration, 36(6), 648-663. https://doi.org/10.1111/1467-9515.00309

Rosa, T. L., Ortolano, S. E., \& Dickin, K. L. (2018). Remembering food insecurity: Low-income parents' perspectives on childhood experiences and implications for measurement. Appetite, 121, 1-8. https://doi.org/10.1016/j.appet.2017.10.035 
Statistics Canada. (2020). Food insecurity during the COVID-19 pandemic, May 2020. (Catalogue number 45280001). https://www150.statcan.gc.ca/n1/en/pub/45-280001/2020001/article/00039-eng.pdf?st=k5kefek4

Strauss, A., \& Corbin, J. (1990). Basics of qualitative research: Grounded theory procedures and techniques. Sage Publications.

Tam, T. (2019). Addressing stigma: Towards a more inclusive health system. Government of Canada. https://www.canada.ca/en/public-health/corporate/publications/chief-publichealth-officer-reports-state-public-health-canada/addressing-stigma-toward-moreinclusive-health-system.html

Tarasuk, V. (2001). Discussion paper on household and individual food insecurity. Health Canada.

Tarasuk, V., Cheng, J., de Oliveira, C., Dachner, N., Gundersen, C., \& Kurdyak, P. (2015). Association between household food insecurity and annual health costs. Canadian Medical Association Journal, 187(14), E429-E436. https://doi.org/10.1503/cmaj.150234

Tarasuk, V., Dachner, N., Hamelin, A. M., Ostry, A., Williams, P., Bosckei, E., Poland, B., \& Raine, K. (2014a). A survey of food bank operations in five Canadian cities. BMC Public Health, 14, 1-11. https://doi.org/10.1186/1471-2458-14-1234

Tarasuk, V., Dachner, N., \& Loopstra, R. (2014b). Food banks, welfare, and food insecurity in Canada. British Food Journal, 116(9), 1405-1417. https://doi.org/10.1108/BFJ-02-2014$\underline{0077}$

Tarasuk, V., Fafard St. Germain, A. A., \& Loopstra, R. (2019). The relationship between food banks and food insecurity: insights from Canada. VOLUNTAS: International Journal of Voluntary and Nonprofit Organizations, 31, 841-852. https://doi.org/10.1007/s11266-01900092-w

Tarasuk, V., \& Mitchell, A. (2020). Household food insecurity in Canada, 2017-18. Research to identify policy options to reduce food insecurity (PROOF).

Thompson, C., Smith, D., \& Cummins, S. (2018). Understanding the health and wellbeing challenges of the food banking system: A qualitative study of food bank users, providers and referrers in London. Social Science \& Medicine, 211, 95-101. https://doi.org/10.1016/j.socscimed.2018.05.030

VERBI Software. (2018). MAXQDA 2018 [computer software]. VERBI Software. maxqda.com.

Waddington, M. (2016) Breastfeeding support in Nova Scotia: Exploring the gap between policy, health professionals' work practices and the everyday experience of mothers facing food insecurity [Unpublished master's thesis]. Mount Saint Vincent University, Halifax, NS.

Wall, K. (2021). Gendered impacts of the COVID-19 pandemic on the proportion of youth neither in employment nor education at the start of the school year. https://www150.statcan.gc.ca/n1/pub/75-006-x/2021001/article/00003-eng.htm

Whittle, H. J., Leddy, A. M., Shieh, J., Tien, P. C., Ofotokun, I., Adimora, A. A., Turan, J. M., Frongillo, E. A., Turan, B., \& Weiser, S. D. (2020). Precarity and health: Theorizing the 
intersection of multiple material-need insecurities, stigma, and illness among women in the United States. Social Science \& Medicine, 245, 1-11.

https://doi.org/10.1016/j.socscimed.2019.112683

Williams, P., McIntyre, L., \& Glanville, N. T. (2010). Milk insecurity: Accounts of a food insecurity phenomenon in Canada and its relation to public policy. Journal of Hunger and Environmental Nutrition, 5(2), 142-157. https://doi.org/10.1080/19320248.2010.489369

Williams, P. L., MacAulay, R. B., Anderson, B. J., Barro, K., Gillis, D. E., Johnson, C. P., Langille, L.L., Moran, S., \& Reimer, D. E. (2012). "I would have never thought that I would be in such a predicament": Voices from women experiencing food insecurity in Nova Scotia, Canada. Journal of Hunger \& Environmental Nutrition, 7(2-3), 253-270. https://doi.org/10.1080/19320248.2012.704740

Williams, P. L. (2014). “I would have never. ..”: A critical examination of women's agency for food security through participatory action research. In Page-Reeves, J. (Ed.), Women redefining the experience of food insecurity: Life off the edge of the table (pp. 275-313). Lexington Books.

Wu, Z., \& Schimmele, C. M. (2005). Food insufficiency and depression. Sociological Perspectives, 48(4), 481-504. https://doi.org/10.1525/sop.2005.48.4.481 